\title{
Publisher Correction: Social Responsibility in a Bilateral Monopoly with Downstream Convex Technology
}

\section{Luciano Fanti ${ }^{1}$ - Domenico Buccella ${ }^{2}$}

\section{Publisher Correction: Journal of Industry, Competition and Trade https://doi.org/10.1007/s10842-020-00343-3}

The Publisher would like to correct the introduced formatting errors and presentation of the mathematical expressions found on page 12 of the pdf version.

In the original publication, all signs (+) and (-) above the mathematical expressions are not properly aligned and displayed.

The Publisher apologizes for the oversight and for any confusion it may have caused.

The original article has been corrected and the updated equations are presented in this article.

$$
\begin{aligned}
& \frac{\partial \pi^{U}}{\partial k}=\frac{\partial \pi^{U}}{\partial c} \frac{\partial c}{\partial k}+\frac{\partial \pi^{U}}{\partial q} \frac{\partial q}{\partial k}=-\frac{k(a-w)^{2}}{4[2(1+v)-k-r]^{3}}<0, \quad k \in[0,1] .
\end{aligned}
$$

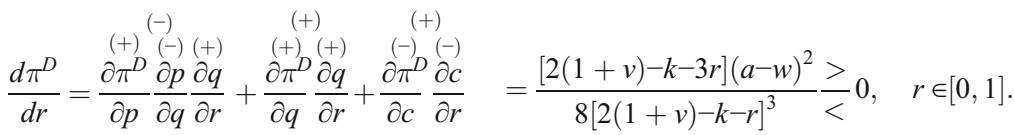

Publisher's Note Springer Nature remains neutral with regard to jurisdictional claims in published maps and institutional affiliations.

The online version of the original article can be found at https://doi.org/10.1007/s10842-020-00343-3

Domenico Buccella

buccella@kozminski.edu.pl

Luciano Fanti

luciano.fanti@unipi.it

1 Department of Economics and Management, University of Pisa, Via Cosimo Ridolfi, 10, I56124 Pisa, PI, Italy

2 Department of Economics, Kozminski University, Jagiellońska Street, 57/59, 03301 Warsaw, Poland 